\title{
Toward Automated Oligo[n]rotaxanes
}

\section{Key words}

oligorotaxanes

iterative synthesis

AT-CUAAC
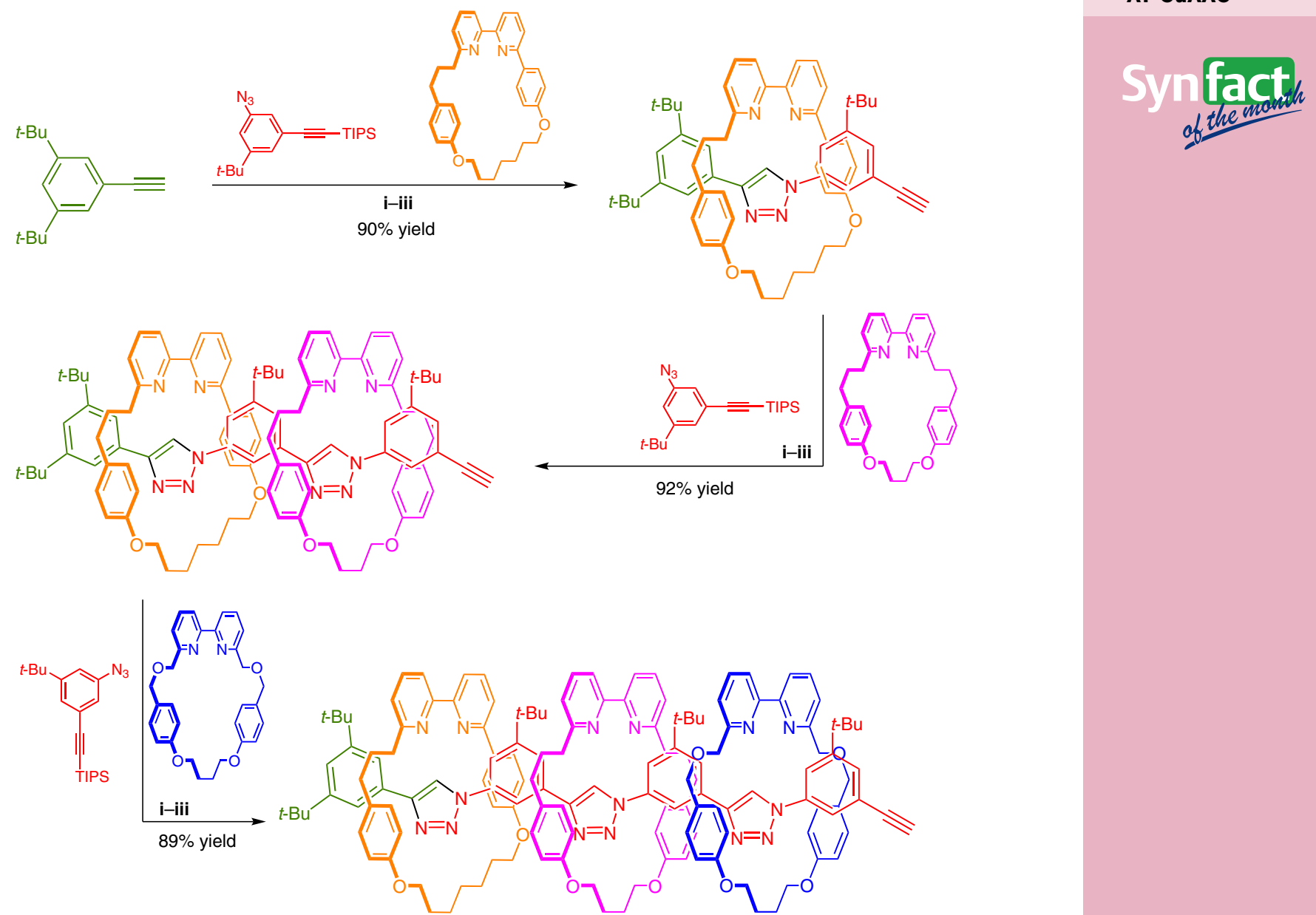

Reaction conditions:

i) $\left[\mathrm{Cu}(\mathrm{MeCN})_{4}\right] \mathrm{PF}{ }_{6}$, DIPEA, EtOH, $100^{\circ} \mathrm{C}$

ii) TFA, $\mathrm{CH}_{2} \mathrm{Cl}_{2}$, r.t.

iii) TBAF, THF, r.t.

Significance: Molecular motors are prime candidates in the development of new materials and sensors. The rotaxane structure has been shown to be able to act as a molecular muscle or molecular computer chip, for which Fraser Stoddart was awarded the 2016 Nobel Prize. The authors demonstrate an iterative synthesis yielding oligorotaxanes in high yields.
Comment: Given the immense importance of rotaxanes, iterative syntheses and their ability to automate syntheses are vital for the widespread application of molecular motors such as rotaxanes. The approach involves an active template coppermediated alkyne-azide cycloaddition (AT-CuAAC) and is applicable to homo- and hetero[n]rotaxanes. 